\title{
Conflict management styles in academic and hospital pharmacy practice areas in affiliated tertiary institutions in Lagos, Nigeria
}

\author{
Emmanuel N. Anyika \\ Department of Clinical Pharmacy \& Biopharmacy, Faculty of Pharmacy, University of Lagos, Nigeria
}

Correspondence: Emmanuel N. Anyika. Address: Department of Clinical Pharmacy \& Biopharmacy, Faculty of Pharmacy, University of Lagos, Lagos - Nigeria. E-mail: emmaboogie22@yahoo.com

Received: May 12, 2013

Accepted: July 15, $2013 \quad$ Online Published:

DOI : $10.5430 /$ jha.v2n4p120

URL: http://dx.doi.org/10.5430/jha.v2n4p120

\section{Abstract}

Background/Objective: Types of conflicts in pharmacy organizations were discussed and conflict management styles by pharmacists in academia and hospital pharmacists in two affiliate tertiary institutions in Lagos, Nigeria were assessed.

Methods: An adapted questionnaire of 20-item inventory for conflict management scale (CMS) for pharmacy was used to obtain responses from hospital pharmacists and pharmacists in academia in the practice areas. The multistage inventory item comprising questions that used four graded scales and appropriate alphabets $\mathrm{A}$ to $\mathrm{D}$ against each column was used in line with the described explanatory model. Scales of A, B, C, and D represent: imposing, settling, avoiding and thwarting respectively. Some items were rephrased and content-validated for clarity to respondents, while the last item (number 20) was introduced to reflect a pertinent issue in conflict management. The instrument was administered in voluntary situation over a period of two weeks; the results were collated and analyzed.

Results: Thirty-one full-time pharmacist lecturers (14 males, 17 females) and 29 registered hospital pharmacists (6 males, 23 females) in the respective institutions completed the questionnaires. The summed scores of dominant and secondary conflict management styles for the two respective groups show that pharmacists in the two practice areas have different approaches to conflict management in workplace. A substantial number of respondents in both settings are either dominantly settling or avoiding in their style.

Conclusion: Training in conflict management and reflective practice is highly recommended for pharmacists, to attain the skills that enhance their interpersonal environment, aimed at making pharmacy practice a very fulfilling and rewarding profession.

\section{Key words}

Conflict management, Hospital pharmacists, Pharmacist educators, Self-reflection, Conflict management scale

\section{I ntroduction}

Conflict between individuals varies from mild disagreement to a win-or-lose, emotion-packed confrontation ${ }^{[1,2]}$. Interpersonal conflict in pharmacy practice is ubiquitous and results from various triggers ${ }^{[3]}$. Types of conflicts in organizations could be inter-individual, intra-group, inter-group or even intra-individual ${ }^{[4]}$. As pharmacists interact within 
their group and between other health professionals and patients, there is increasing possibility of interpersonal conflicts ${ }^{[5,6]}$. Conflict when poorly managed can become complex and hazardous ${ }^{[7]}$. Unsuccessful conflict management is a prime cause of stressful work environments, power games, patient and employee dissatisfaction, poor quality of care, and increased costs ${ }^{[8]}$. Conflict could be in the form of horizontal violence, which ranges from gossiping, unnecessary criticism, intimidation, passive aggression, withholding information, insubordination to bullying ${ }^{[9]}$. In the academia, conflict could ensue from inequitable workload distribution, power games, differences in cultural values, skewed gender support, favoritism, lack of commitment, mentoring and academic focus.

Iglesias and de Bengoa Vallejo ${ }^{[10]}$ reported the predominant conflict management styles used by Spanish nurses working in the university (academia) and clinic settings respectively. Khanfar et al. ${ }^{[11]}$ showed the cultural differences in leadership styles of pharmacist preceptors, who worked in teams and cared for patients from a variety of cultures. Power imbalance between the lecturer and the student on the one hand, and patient and care giver on the other, is prone to conflict ${ }^{[12]}$. Destructive conflicts tend to escalate a cyclic conflict and violence, and may develop conflict helix ${ }^{[13]}$. A pharmacy organization with diversity of employees of professional, semi-professional, skilled and technical staff - makes pharmacy susceptible to constant confrontation ${ }^{[3,14]}$. Conflicts of structural origin include inequitable salary structure, unchallenging job content, and lack of progression. A carry-over of unresolved conflict could cause a caregiver to refuse consultation of a technically superior staff, at the expense of the patient ${ }^{[15]}$. The ability to cope with and manage conflict is crucial for the successful interpersonal and inter-professional interactions for nurses ${ }^{[16,17]}$ and surgeons ${ }^{[18]}$. Conflict style inventories and models have been used for decades to prompt self-reflection, self-awareness and enhance collaboration in conflict management ${ }^{[1,5,19-21]}$.

\section{Methods}

A 19-item conflict management scale (CMS) instrument for pharmacy by Austin et al. ${ }^{[5]}$ was adapted and used for the study. It comprised a structured questionnaire that underwent a multistage development process and earlier tested for validity and reliability. It was content-validated to avoid ambiguity to the respondents, and the last item was added to obtain a 20-item explanatory model (see Table 1). Four-point scale was used, with behaviorally oriented question items (rather than requiring individuals to speculate on internal motivation). Point-scaling was similarly behaviorally-oriented to give the terms: "usually”, "sometimes", "rarely", and "hardly"; and to avoid a middle-of-the-road response. Each question has four graded scales and appropriate alphabets A - D against each column in the described explanatory model. The scale of A is imposing, B is settling, C is avoiding, and D is thwarting, on which the respondent circles the most appropriate letter for each question. The instrument was administered in voluntary situation to 32 full-time pharmacist lecturers in the faculty of pharmacy and 35 registered hospital pharmacists in different units in the teaching hospital. Included were hospital pharmacists on afternoon and night duties, to capture the behavioral responses related to time and hours of work. Respondents were asked to think about a few recent situations where they had been involved in a stressful conflict with someone else. This could be a situation at work, in their personal life, or even an unexpected encounter with a stranger. They were then asked to circle the letter in the column that best characterizes what worked best for them in situations like the ones they had thought about. The number of each alphabet circled in each column was summed up, the gender distribution and percentages for each score were summarized for the respective groups.

\section{Results}

Thirty-one (31) lecturers (14 males, 17 females) and 29 hospital pharmacists (6 males, 23 females) completed the questionnaires, giving a total of 60 respondents. The dominant conflict management style from this model is the letter most frequently circled by the respondent, while the secondary conflict management style is the next most-frequently circled letter. 
Table 1. The adapted conflict management scale (cms)

\begin{tabular}{|c|c|c|c|c|}
\hline When I am involved in a conflict situation with another person & Usually & Sometimes & Rarely & Hardly \\
\hline I have strong beliefs about how the situation should resolve & A & $\mathrm{D}$ & $\mathrm{C}$ & $\mathrm{B}$ \\
\hline it is usually because the other person has inappropriately forced his/her perspective & $\mathrm{C}$ & $\mathrm{B}$ & $\mathrm{D}$ & A \\
\hline I am willing to compromise in order to get a resolution & $\mathrm{B}$ & $\mathrm{C}$ & A & $\mathrm{D}$ \\
\hline I use many different strategies to convince him/her of my point of view & $\mathrm{D}$ & $\mathrm{B}$ & A & $\mathrm{C}$ \\
\hline I expect that both of us will have to give-and-take to get to a satisfactory outcome & $\mathrm{C}$ & $\mathrm{B}$ & A & $\mathrm{D}$ \\
\hline I firmly stake out and clearly explain my position & A & $\mathrm{D}$ & $\mathrm{B}$ & $\mathrm{C}$ \\
\hline I am willing to "lose the battle in order to win the war" & $\mathrm{D}$ & A & $\mathrm{C}$ & B \\
\hline it is most important to first identify all the things we both agree upon & $\mathrm{B}$ & $\mathrm{D}$ & $\mathrm{C}$ & A \\
\hline I find it difficult to clearly articulate my position and reasons & $\mathrm{C}$ & $\mathrm{D}$ & $\mathrm{B}$ & A \\
\hline I believe it is important to be consistent and firm with my principles & A & $\mathrm{D}$ & $\mathrm{C}$ & $\mathrm{B}$ \\
\hline I avoid addressing someone in an inflammatory manner & $\mathrm{C}$ & B & $\mathrm{D}$ & A \\
\hline $\begin{array}{l}\text { I will use non-verbal communication or silence as a strategy to convey what I am } \\
\text { thinking }\end{array}$ & $\mathrm{D}$ & $\mathrm{C}$ & $\mathrm{B}$ & A \\
\hline I believe "give and take” is a way to avoid or withdraw from a responsibility & A & $\mathrm{D}$ & $\mathrm{C}$ & $\mathrm{B}$ \\
\hline I feel drained and exhausted & $\mathrm{C}$ & B & A & $\mathrm{D}$ \\
\hline I feel it is my responsibility to reach a compromise & B & $\mathrm{C}$ & $\mathrm{D}$ & A \\
\hline I try hard not to hurt the other person's feelings & $\mathrm{C}$ & B & $\mathrm{D}$ & A \\
\hline it is important to raise all issues immediately and get them in the open & A & $\mathrm{B}$ & $\mathrm{D}$ & $\mathrm{C}$ \\
\hline I believe it is better to anticipate and prevent conflict & $\mathrm{C}$ & $\mathrm{B}$ & $\mathrm{D}$ & A \\
\hline I believe "all is fair in love and war" & $\mathrm{D}$ & $\mathrm{C}$ & A & $\mathrm{B}$ \\
\hline I prefer the other person to shift position & A & $\mathrm{D}$ & $\mathrm{B}$ & $\mathrm{C}$ \\
\hline
\end{tabular}

For dominant conflict management styles in Table 2, about $13 \%$ of the respondents were imposing, 42\% were settling, $35 \%$ were avoiding and 10\% were thwarting. For secondary conflict management styles, 26\% were imposing, 19\% settling, 45\% avoiding, and 10\% thwarting. These show high percentages of lecturers using avoiding style both for dominant and secondary conflict management styles (35\% and 45\%) respectively. Proportionally, women appeared more imposing than men in the dominant domain (17\%: 7\%), and also more thwarting (12\%: 7\%). For the secondary conflict management style, $26 \%$ were imposing and $10 \%$ thwarting.

Table 2. Summed scores of dominant and secondary conflict management styles for pharmacists in academia

\begin{tabular}{|c|c|c|c|c|c|c|c|c|c|}
\hline \multirow{2}{*}{ Gender } & \multirow{2}{*}{ Number } & \multicolumn{4}{|c|}{ Dominant conflict management style } & \multicolumn{4}{|c|}{ Secondary conflict management style } \\
\hline & & $\mathbf{A}$ & $\mathbf{B}$ & $\mathbf{C}$ & $\mathbf{D}$ & $\mathbf{A}$ & $\mathbf{B}$ & $\mathbf{C}$ & $\mathbf{D}$ \\
\hline Male & 14 & 1 & 5 & 7 & 1 & 4 & 3 & 6 & 1 \\
\hline Female & 17 & 3 & 8 & 4 & 2 & 4 & 3 & 8 & 2 \\
\hline Total (\%) & $31(100)$ & $4(13)$ & $13(42)$ & $11(35)$ & $3(10)$ & $8(26)$ & $6(19)$ & $14(45)$ & $3(10)$ \\
\hline
\end{tabular}

In Table 3, about $28 \%$ of the hospital pharmacists were imposing, $41 \%$ settling, $24 \%$ avoiding, and $7 \%$ thwarting in the dominant setting. For secondary conflict management style, 10\% each were either imposing or thwarting, while 38\% were settling and $41 \%$ of the respondents avoiding. Proportionally, men were slightly more imposing than the women (33\%: $26 \%$ ) in the hospital setting, from the dominant management style perspective.

Table 3. Summed scores of dominant and secondary conflict management styles for hospital pharmacists

\begin{tabular}{|c|c|c|c|c|c|c|c|c|c|}
\hline \multirow{2}{*}{ Gender } & \multirow{2}{*}{ Number } & \multicolumn{4}{|c|}{ Dominant conflict management style } & \multicolumn{4}{|c|}{ Secondary conflict management style } \\
\hline & & A & B & C & D & A & B & C & D \\
\hline Male & 6 & 2 & 1 & 3 & 0 & 0 & 4 & 1 & 1 \\
\hline Female & 23 & 6 & 11 & 4 & 2 & 3 & 7 & 11 & 2 \\
\hline Total (\%) & $29(100)$ & $8(28)$ & $12(41)$ & $7(24)$ & $2(7)$ & $3(10)$ & $11(38)$ & $12(41)$ & $3(10)$ \\
\hline
\end{tabular}




\section{Discussion}

From the above results, pharmacists in the two practice areas apparently have different approaches to conflict management. They fit into the four conflict management modes when faced with conflict and also showed dominant as well as secondary conflict management styles. Individual preferences appear to be linked to individual conflict management style ${ }^{[22]}$. Pharmacists in the academia would need to be more imposing than expressed, especially when dealing with students, to achieve results and assume a more settling posture when dealing with colleagues. Academic environments are usually associated with human capital development, teamwork, seminars, conferences, research and results. It is important that pharmacists take into consideration the interpersonal requirements of such responsibilities and use the right strategy to achieve success. A reasonably high percentage (35\%) of academics are dominantly avoiding, while (10\%) are thwarting in an environment where knowledge capital thrives on collaboration and settling, free flow of information, and good communication for goal achievement. Avoidance of conflict by ignoring a student's misdemeanor during a class could be more rewarding than escalating the conflict by confrontation. Increasing the knowledge of self-reflection and problem-solving capacity among professionals will provide opportunities for conflict de-escalation ${ }^{[19]}$. Each pharmacist tends to use one or more of the above four strategies more than the others. The key to managing conflict well is choosing and executing the strategy that best fits the situation. Collaborating with colleagues and other health professionals promotes creative problem-solving, which is a way of fostering mutual respect and rapport. However, many conflict situations are either very urgent or too trivial to justify the time it takes to collaborate or to settle. Many conflict situations can be handled by one strategy other than collaboration ${ }^{[23]}$, provided the pharmacist understands the interpersonal conflict situations ${ }^{[2]}$; and use appropriate conflict management strategy for each situation.

Time pressure tends to generate conflict in hospital pharmacy settings, especially during peak periods. The value placed on the existing relationship with the other party, and the power at the disposal of the pharmacist relative to the other party - all influence conflict management style used. Resolution of drug related problems based on the tacit knowledge of the pharmacist may require an imposing style more than avoiding or settling - where the majority of the respondents ( $77 \%$ and $65 \%)$ in academics and hospital practice respectively fall into. Collaboration and settling are very good strategies for handling conflicts over important issues. Counseling a patient on the right route of drug administration, compliance and adherence to dosage regimen, all require some degree of imposing and settling or cooperation of the patient for optimal therapeutic outcomes, not avoiding or worse still thwarting style. As care givers, pharmacists should minimally deploy thwarting strategy in workplace, except if it is in the best interest of the patient. For moderately important issues, settling and avoiding strategies could be quick ways of resolving issues without straining the relationship with other members of the health team or patients. Avoiding strategy is best where there is a clear advantage of waiting to resolve the conflict. Patients are often tired and impatient at the point of arrival at the pharmacy for prescription filling. Their complaints over the counter may be genuine or trivial. Pharmacists should dowse the potential conflict situation by avoiding it, bearing in mind the relative unimportance of some of the situations.

Since the model used is based on direct and indirect communication styles as well as principled and pragmatic worldview, pharmacists should understand the conflict response styles of patients, colleagues and other health professionals to manage conflict properly. Addressers (first-steppers and confronters) could request for pharmaceutical services in a confrontational manner or by other means that undermine due process. Concealers are feeling-swallowers, subject changers and avoiders. Attackers are those colleagues, other caregivers and patients, who cannot keep their feelings to themselves. There are front and behind-the-back attackers. Either way, their feelings are known and conflict could be resolved by avoiding or settling depending on the nature of the conflict. Pharmacy educators should therefore go beyond teaching communication skills in general, to the teaching of conflict management skills in particular, for enhanced competence in work-place. As knowledge reservoirs and think-tanks, academics should not only look inwards for sustainable solution to problems in academia, but could intervene and resolve issues in a contemporary world faced with value, character, moral and ethical crises ${ }^{[24]}$. They should join hands with conflictologists, and study the various dimensions and dynamics of conflict in different pharmacy practice areas and groups, with a view to identifying, diagnosing and managing these conflicts in the best interest of the patients, the profession and the society at large. 
The limitations of the study include the use of only two affiliate institutions, which in turn limits the number and gender of pharmacists to those in the work settings studied. Also hospital pharmacy practice is dominated by women in our environment, and would introduce the bias of concluding on the dominant conflict management style in the hospital setting. A study involving the use of pharmacist lecturers in accredited faculties of pharmacy in Nigeria and hospital pharmacists in the university teaching hospitals would give a more robust and generalizable result.

\section{Conclusion}

Causes of conflict in pharmacy practice settings are numerous due to the changing situations. They require multiple and more creative approaches to respond to conflict and be able to transform them to more beneficial outcomes on a daily basis. Learning how to deal effectively with conflict requires skills and commitment, bearing in mind that the most appropriate method of managing conflict could be situational. Training in conflict management is recommended for pharmacists and at undergraduate level, to attain the skills that will enhance their interpersonal environment for the benefit of the patients, other health professionals, and the larger society. Academics should carry out in-depth study of various dimensions and dynamics of conflict in pharmacy practice and explore more reflective and creative ways of coping with them.

\section{Competing interests}

The author declares that he has no competing interest.

\section{Acknowledgements and funding}

I acknowledge Dr. Zubin Austin for permitting the adaptation and use of "Conflict management scale for pharmacists". I also acknowledge all the pharmacists in academia and hospital in the two institutions used for the study. The research was funded by the author.

\section{References}

[1] Herzog AC. Conflict resolution in a nutshell: tips for everyday nursing. Spinal Cord Injury Nursing 2000; 17: 162-6.

[2] Kirchoff, N, Adams, JR. Conflict management for project managers. Drexel Hill: Project Management Institute, 1982.

[3] Austin Z, Gregory PAM, Martin C. Pharmacists' management of conflict in community practice. Research in Social \& Admin Pharm 2010; 6. ISSN: $1934-8150$.

[4] Riggio, RE. Introduction to industrial/organizational psychology, 4th ed. Upper Saddle River, NJ: Prentice Hall, 2003.

[5] Austin Z, Gregory PAM, Martin C. A conflict management scale for pharmacy. American J. Pharm Educ 2009; 73(7) Article 122: 1- 8.

[6] Worley MM, Schommer JC. Pharmacists' therapeutic relationships with older adults: the impact of participative behavior and patient centredness on relationship quality and commitment. J. Social \& Admin. Pharmacy 2002; 19: 180-9.

[7] Graham S. The effects of different conflict management styles on job satisfaction in rural health settings. Economics \& Business Journal: Inquiries \&Perspectives 2009; 2(1): 71-85.

[8] Kantek F, Kavla I. Nurse-nurse manager conflict: how do nurse managers manage it? The Health Care Manager 2007; 26(2): 147-151.

[9] Baltimore J. Fact or fiction? Nursing Management 2006; 28 - 36. PMid: 16651900. http://dx.doi.org/10.1097/00006247-200605000-00008

[10] Iglesias MEL, De Bengoa, Vallejo RB. Conflict resolution styles in the nursing profession. Contemporary Nurse. [Internet] 2013; 43(1): 74-81. Available from: http://pubs.e-contentmanagement.com (30 April 2013, date last accessed).

[11] Khanfar NM, Harrington CA, Alkhateeb FM, Kaifi BA. Cultural differences in leadership styles of pharmacist preceptors. Business and Management Research. [Internet] 2013; 2: 1-17. Available from: www.sciedu.ca/bmr (30 April 2013, date last accessed).

[12] Holton, SA. Cracks in the Ivory Tower: Conflict management in the classroom and beyond. [Internet] Available from: http://www.podnetwork (16 August 2011, date last accessed). 
[13] Deutsch, M. The resolution of conflict. New Haven: Yale University Press, 1973.

[14] Okolo EN. Conflict resolution strategies in the pharmacy. Hospital Pharm. [Internet] 1985; 20(4): 245-7. Available from: http://www.ncbi.nlm.nih.gov/pubmed/10270730 (16 August 2011, date last accessed).

[15] Andrew LB. Conflict management, prevention, and resolution in medical settings. Physician Executive 1999; 38-42. PMid: 10557483.

[16] Montoro-Rodriguez J, Small J. The role of conflict resolution styles on nursing staff morale, burnout and job satisfaction in long-term care. Journal of Aging Health 2006; 18(3): 385-406. PMid: 16648392. http://dx.doi.org/10.1177/0898264306286196

[17] Gerardi D. Using mediation techniques to manage conflict and create healthy work environments. American Assoc Critical Care Nurses and Clinical Issues. [Internet] 2004; 15: 182-195. Available from: http://www.managingconflict.com/(16 August 2011, date last accessed).

[18] Lee L, Berger D, Awad S, Bradt M, Martinez G, Brunicardi F. Conflict resolution: practical principles for surgeons. World J. Surgery 2008 Sept; 12: 187-196.

[19] Ross A, King N, Firth J. Relationships and collaborations: interpersonal relationships and collaborative working: Encouraging reflective practices. American Nursing Assoc. Periodicals 2005; 10: 95-103.

[20] Robbins, SP, Coulter, M. Management, 9th ed. Upper Saddle River, New Jersey: Pearson Prentice Hall, 2007, 435-7.

[21] Ruble TI, Thomas KW. Support for a two-dimensional model of conflict behavior. Organizational Behavior and Human Performance 1976; 143-155. http://dx.doi.org/10.1016/0030-5073(76)90010-6

[22] O’Mara K. Communication and conflict resolution in emergency medicine. Emerg. Med Clinics North America 1999; 17: 451-9. http://dx.doi.org/10.1016/S0733-8627(05)70071-7

[23] De Bono, E. Conflicts. A better way to resolve them. London: Harrap. [Internet] 1985. Available from: http://www.fao.org/docrep/w7504e07.htm (16 August 2011, date last accessed).

[24] Bhaskaran, MW. Role of academics in conflict resolution. [Internet] 2003. Available from: http://www.mkgandhi.org/nonviolence/con_reso.htm (8 August 2011, date last accessed). 